\section{(6) OPEN ACCESS}

\title{
'Miscarriage or abortion?' Understanding the medical language of pregnancy loss in Britain; a historical perspective
}

\author{
Andrew Moscrop
}

\begin{abstract}
Correspondence to Dr Andrew Moscrop, Narrowboat St Crispin, Weirs Lane, Oxford OX1 4UP, UK;

andrewmoscrop@post.harvard. edu
\end{abstract}

Received 5 September 2012 Revised 23 January 2013 Accepted 28 January 2013 Published Online First 21 February 2013

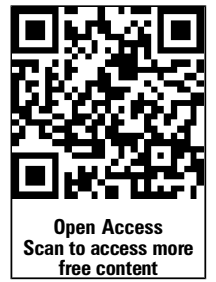

To cite: Moscrop A. Med Humanit 2013;39:98-104.

\begin{abstract}
Clinical language applied to early pregnancy loss changed in late twentieth century Britain when doctors consciously began using the term 'miscarriage' instead of 'abortion' to refer to this subject. Medical professionals at the time and since have claimed this change as an intuitive empathic response to women's experiences. However, a reading of medical journals and textbooks from the era reveals how the change in clinical language reflected legal, technological, professional and social developments. The shift in language is better understood in the context of these historical developments, rather than as the consequence of more empathic medical care for women who experience miscarriage.
\end{abstract}

\section{INTRODUCTION: \\ 'MISCARRIAGE OR ABORTION?'}

'It is curious', began a letter to the Lancet published in 1985 , 'that, in a language as descriptively rich as English, no clear distinction is made between a spontaneous and an induced expulsion of the contents of the uterus in early pregnancy.' The communication, printed under the heading 'Miscarriage or Abortion?', came from a group at St Mary's Hospital London led by Richard Beard, then Professor of Obstetrics and Gynaecology. ${ }^{1}$ It continued: 'Doctors use the word 'abortion' regardless of whether it was a spontaneous or induced event, yet our patients always speak of 'miscarriages' unless they have had a termination of pregnancy. It seems likely that the words have been interchangeable for many centuries...' Beard et al described the offence caused to those women who miscarry 'by the use of the word abortion to describe their condition'. They appealed to doctors and all health professionals 'to start using the word miscarriage rather than abortion for a spontaneous pregnancy loss before 28 weeks of pregnancy.'

Seven years later psychologist Beverly Chalmers asserted that 'publications in the British Journal of Obstetrics and Gynaecology have taken heed'. She observed 'a change in terminology used before and after the editorial (sic) by Beard et al'. ${ }^{2}$ In a 1997 British Medical Journal (BMJ) editorial Emeritus Professor of Obstetrics Geoffrey Chamberlain also credited Richard Beard with moving clinicians towards a more empathetic practice. ${ }^{3}$

If the terms 'miscarriage' and 'abortion' had, among doctors, been 'interchangeable for many centuries' as Beard and his colleagues suggested, why did they call for change in 1985? Did medical language change subsequently? If so, why? What factors, other than Beard's Lancet letter, might explain a change in the medical language of early pregnancy loss?

With these questions in mind, I hand-searched the Lancet, BMJ and British Journal of Obstetrics and Gynaecology for indexed references to 'miscarriage', 'abortion', 'spontaneous abortion' and 'early pregnancy loss' between the years 1960 and 2010. These references were reviewed and coded in an effort to chart the changing use of terminology and understand those changes in the context of changing medical knowledge and clinical practice. I also obtained and reviewed consecutive editions of the seminal Ten Teachers' textbooks of Obstetrics and of Gynaecology (first published in London respectively as Midwifery in 1917 and as Diseases of Women in 1919 and in print ever since). The 10th (1961) to 14th (1985) editions of Obstetrics (nee Midwifery), and the 9th (1953) to 16th (1995) editions of Gynaecology (nee Diseases of Women) were used to gain insight into established textbook knowledge and attitudes available to students and clinicians over time.

My interpretation of these sources has been influenced by my experiences of working as a general practitioner, as a doctor in an emergency gynaecology department, and as a researcher conducting a clinical study of early pregnancy loss as well as by my readings of feminist accounts of abortion law, ${ }^{45}$ ultrasound, ${ }^{6}$ the medicalisation of pregnancy ${ }^{78}$ and of pregnancy loss..$^{9} 10$

\section{TERMINOLOGY IN MEDICAL JOURNALS AND TEXTBOOKS}

In 1992, Beverly Chalmers perceived the impact of Beard's 'Miscarriage or Abortion?' Lancet letter upon papers published in the British Journal of Obstetrics and Gynaecology. ${ }^{2}$ She had reviewed the titles of articles on the subject of early pregnancy loss at the beginning and end of the 1980s and found that 'whereas almost all the papers at the start of the decade used the term 'abortion' in their titles, none of those published later did so.'

This trend can be analysed in greater detail. The graph in figure 1 plots the annual incidence of articles published on the subject of early pregnancy loss in the British Journal of Obstetrics and Gynaecology from 1975 to 1999; it differentiates between those using 'abortion' and 'miscarriage' in their titles. Around 1986, a definitive flip occurred in the titles of articles referring to early pregnancy loss: from the exclusive use of 'abortion' to 'miscarriage' as the descriptor. 


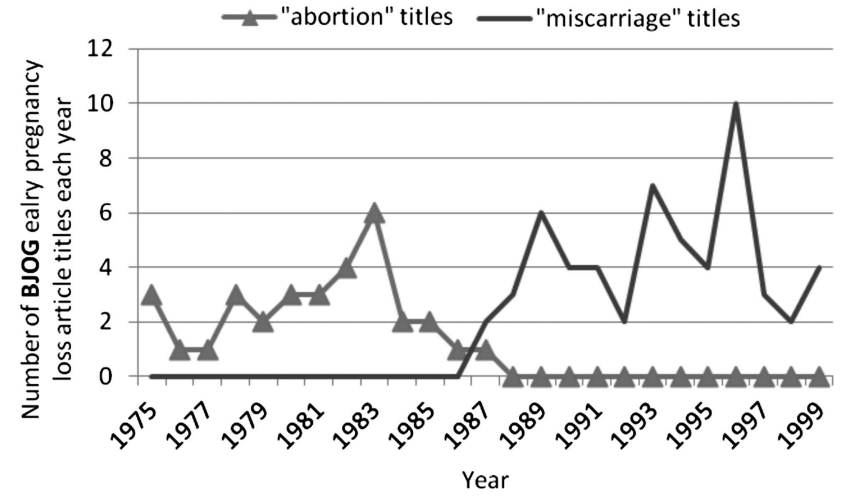

Figure 1 Annual incidence of article titles using 'abortion' and 'miscarriage' to refer to early pregnancy loss in the British Journal of Obstetrics and Gynaecology between 1975 and 1999.

Meanwhile, in the $B M J$, use of 'abortion' or 'spontaneous abortion' in article titles referring to early pregnancy loss declined slowly between 1985 and 1995 (See figure 2): thereafter 'miscarriage' is always employed.

In the Lancet a shift in the terminology of early pregnancy loss is less obvious, but a divergence between the incidences of 'abortion' and 'miscarriage' becomes apparent after 1985 (see figure 3).

In the BMJ and Lancet, the gradual change in published article titles suggests a gradual shift in terminology used by contributors, rather than deliberate editorial policy on the part of the journals. Closer inspection of published articles supports this conclusion of variable and slow-changing use of terms among doctors. In 1987, a paper on management of threatened miscarriage published in the $B M J$ consistently uses the term 'miscarriage' throughout; ${ }^{11}$ yet while some correspondents responding to the article used only 'miscarriage' in their letters, ${ }^{12}$ others used the term 'abortion' exclusively. ${ }^{13}$ Similarly, in 1991 the BMJ published an editorial titled 'Recurrent miscarriage' ${ }^{14}$ to which two correspondents responded: one letter headed 'Recurrent miscarriage'; ${ }^{15}$ the other, 'Recurrent abortion'. ${ }^{16}$

Medical journals in fact appear slow to have acknowledged the changing use of language by their readers: 'Miscarriage' appears for the first time in the index of the BMJ in 1978, and until 1999 readers looking under ' $M$ ' were advised 'Miscarriage-see abortion'. In the indices of the Lancet, 'miscarriage' only appears after 1988 and readers were referred to 'abortion' until 1994.

As late as 1995, the Ten Teachers (who by then numbered two women alongside eight male contributors), in the 16th edition of their Gynaecology text, continued, as in earlier editions, to refer to early pregnancy loss as 'abortion'. They began the chapter on this subject by asserting 'the terms abortion and miscarriage are synonymous'. They continued to use the terms interchangeably in their text, but conceded 'generally miscarriage carries connotations of spontaneous loss and is best used when talking to women'.

The actual clinical language used in conversation between doctors and patients at this time is not recorded. However, in 1988 one doctor felt compelled to write to the $B M J$, advising that:

\begin{abstract}
Abortion was discussed during a recent phone in programme on BBC Radio Derby. A number of women listeners expressed their objection to the term "abortion" when it referred to the spontaneous event. They were unanimous in their wish that the terms "miscarriage" should be used instead... ${ }^{17}$
\end{abstract}

Evidently, the shift in medical terminology occurred slowly among doctors as represented by the authors of journal articles, correspondence and textbooks. The following sections consider some of the factors apparent in the medical literature of the time that may have prompted Richard Beard to call for change in 1985 and that would have enabled a change in medical terminology.

\section{ABORTION LAW}

Before the 1967 Abortion Act eased legal impediments to ending an unwanted pregnancy, the distinction between 'spontaneous' and 'induced' abortion alluded to in medical journals and textbooks of the time remained academic.

Although many abortions were carried out illegally, women who developed problems afterwards would rarely disclose their procedure for fear of criminalising themselves. Instead, they might claim to have had a 'spontaneous' abortion (miscarriage). Meanwhile, clinicians would not normally have been able to distinguish between 'spontaneous' and 'induced' abortions, despite their recognition that many cases of early pregnancy bleeding (particularly instances of 'septic abortion', in which pregnancy loss was complicated by infection) were accounted for by illmanaged illegal abortion attempts.

In 1961 an article in the BMJ observed that:

It is notoriously difficult to obtain reliable histories from patients suffering from septic abortion, and it is often suspected that criminal interference, which the patient will not acknowledge, has taken place. ${ }^{18}$

A 1964 BMJ article on the subject of 'bleeding in early pregnancy' spoke of 'criminal interference' that 'such interference is so often denied, even when it is obvious, that many doctors do not inquire about the possibility. ${ }^{19}$

Textbooks of the era exhibit similar suspicions. In 1966, the year before the Abortion Act was passed, the 11th edition of Obstetrics by Ten Teachers advised doctors on how they might discern an induced abortion when, presumably, it was not admitted by the patient: 'the presence of abrasions or lacerations
Figure 2 Annual incidence of article titles using 'abortion' and 'miscarriage' to refer to early pregnancy loss in the $B M J$ between 1975 and 2010.

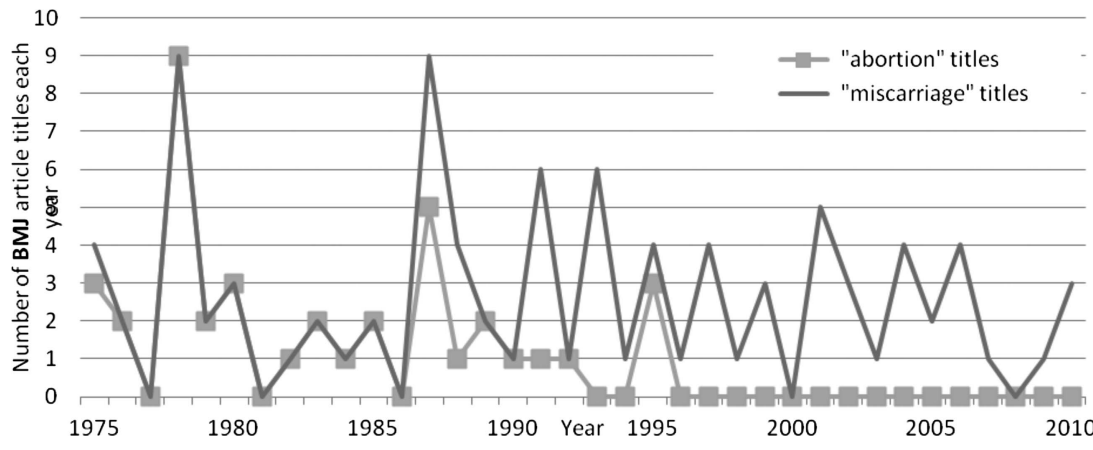


Figure 3 Annual incidence of article titles using 'abortion' and 'miscarriage' to refer to early pregnancy loss in the Lancet between 1975 and 2010.

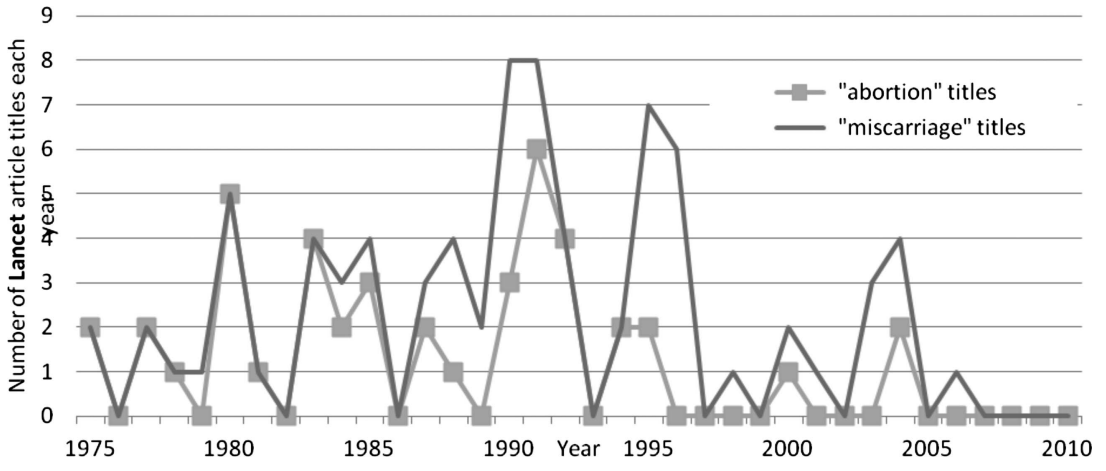

in the genital tract... strongly suggests criminal interference.' Nonetheless, 'criminal abortion' was listed alongside other presumptive, but apparently indeterminable, 'causes of abortion' that were 'to a certain extent, theoretical and arbitrary'. These included: 'reflex stimulation of the uterus by emotional disturbances' and 'coitus during the first 3 months of pregnancy'.

Before 1967, statutes relating to pregnancy termination prevented doctors discerning abortions that were 'induced' from those that were 'spontaneous'. Distinction between 'abortion' and 'miscarriage' was impossible in clinical practice and meaningless in clinical language.

\section{ULTRASOUND TECHNOLOGY}

The 'clinical varieties of abortion' had long been distinguished and systematised in medical textbooks. With the aid of illustrative line drawings and monochrome photographs of pathological specimens, consecutive editions of the Ten Teachers' texts had elaborated an inventory of: threatened, inevitable, complete, incomplete, septic, missed and habitual abortions.

Since they were first described, the difficulty of distinguishing these clinical varieties in practice had remained unchanged. Before ultrasound technologies permitted clinicians to look inside the wombs of women experiencing pain or bleeding in early pregnancy, it was impossible to discern the varieties of abortion and distinguish these from a potentially life threatening 'tubal' (ectopic) pregnancy. Often the only effective diagnostic method was hospital admission and a prolonged period of observation. The pathological specimens featured in textbooks of this era attested to an impasse: until the uterus expelled its content, or emergency surgery was carried out, or the mother died, it might be impossible to discern the cause of bleeding occurring in early pregnancy. Ultimate diagnostic knowledge was as likely to be obtained by the hospital pathologist as by the clinician.

Ultrasound changed this. Evidence produced in the mid-1970s had endorsed 'the diagnosis of early pregnancy failure by sonar' ${ }^{20}$ and demonstrated the benefits of this technique over the traditional methods of urinary hormone assays and clinical judgement. ${ }^{21}$ The early years of the 1980 s saw elaboration of understanding of ultrasound's value in the specific context of early pregnancy problems ${ }^{22} 23$ along with growing acknowledgement of its routine potential in early pregnancy. ${ }^{24}$

Demonstrating the timely relevance of ultrasound to understanding of 'spontaneous abortion' and the speed of developments around this time, in 1984 a Canadian research group claimed the second report on the frequency of spontaneous abortions in ultrasound-assessed intact pregnancies ${ }^{25}$ just 6 weeks after a Dutch group had claimed the 'first report' of this subject. ${ }^{26}$ gave ultrasound only a limited place in the assessment of early pregnancy bleeding ('threatened abortion'). A single sentence alluded to the role of the unfamiliar-sounding technology: 'After the $12^{\text {th }}$ week the ultrasonarscope (e.g. Sonicaid) may be used to determine whether the fetus is alive.' Five years later, in the 14th edition of that textbook, the single sentence on the use of ultrasound in threatened abortion had expanded to become a paragraph that sounded very much more enthused:

As soon as the initial bleeding has stopped an ultrasonic scan is performed. This will reveal whether or not the pregnancy is intact...

...With a high resolution real time mechanical sector scanner cardiac activity can consistently be recognised at 8 weeks.

During the early 1980s, developments in relation to ultrasound technology and its application in the context of early pregnancy problems changed clinical practice. By the middle of the decade, a survey of general practitioners' management of bleeding in early pregnancy found that 'the patient was sent to hospital for ultrasound examination as an outpatient by 1045 $(81 \%)$ respondents'. ${ }^{27}$ In 1990 , the 15 th edition of the Ten Teachers text reflected that:

The management of patients with bleeding early pregnancy has been enormously simplified by ultrasound. Prior to ultrasound, patients with a missed abortion often spent many days in hospital until it became clinically clear that the pregnancy had ended.

Textbooks replaced pictures of pathological specimens from early pregnancy with reproductions of ultrasound images and similar images could now be reproduced by doctors in clinics equipped with their own ultrasound scanner. For the first time in the medical history of early pregnancy, hospital clinicians with appropriate hardware could render technical, textbook knowledge of systematised early pregnancy pathologies directly and in 'real time' from the female bodies lying before them.

Richard Beard's 1985 'miscarriage or abortion?' Lancet letter attests to the potential impact of ultrasound technology upon medical terminology, and to the application of technologically determined medical language to women's experiences:

'Intrauterine death at $\mathrm{x}$ weeks' is really a more satisfactory way of accurately describing what has happened and is appropriate now that ultrasound can distinguish between the blighted ovum and a fetus that has developed but died. ${ }^{1}$

Accurate descriptions and conformity in language would become a feature of new technology-derived medical knowledge and physicians' new diagnostic authority.
In 1980, the 13th edition of Gynaecology by Ten Teachers 


\section{THE BASIS OF PERINATOLOGY}

By the 1980s, thanks to legal and technical developments, early pregnancy loss could increasingly be diagnosed by doctors.

However, it remained ambiguously designated: 'abortion' was often used in the medical literature without a clarifying prefix ('spontaneous' or 'induced') to describe spontaneous pregnancy loss, ${ }^{28}$ induced termination of pregnancy ${ }^{29}$ or (deliberately exploiting the dual meaning of the term) both. ${ }^{30}$

Early pregnancy loss also remained ambiguously positioned: it had not yet been claimed by a specialist group. Research on the subject frequently appeared in the general medical journals and was carried out by a wide range of contributors (including paediatricians, ${ }^{31}$ medical geneticists, ${ }^{32}$ psychiatrists, ${ }^{33}$ epidemiologists, ${ }^{34}$ general physicians ${ }^{35}$ and haematologists $\left.{ }^{36}\right)$. In 1980, the chapter on 'Abortion' (miscarriage) appeared for the last time in the 13th edition of Obstetrics by Ten Teachers and materialised for the first time in the 13th edition of their Gynaecology text. Early pregnancy loss did not gain a home in a specialist niche until the growth of perinatology.

Richard Beard (of the 1985 'Miscarriage or abortion?' Lancet letter) published the 1st edition of a defining textbook on 'Fetal physiology and medicine' in 1976. Aptly, the textbook was subtitled 'the basis of perinatology'. 1976 also saw the founding of the British Paediatric Perinatal Group (BPPG). The Journal of Perinatal Medicine was founded in 1973; Clinics in Perinatology in 1974; Advances in Perinatal Medicine in 1981; and The Journal of Perinatology in 1984. In 1979, The Lancet published a series on Better Perinatal Health. In 1982, the BPPG created a training programme offering accreditation in Perinatal Paediatrics and in 1985 the BPPG dropped the 'paediatric' from its title to become the British Association of Perinatal Medicine. New journals, qualifications and associations evidence the establishment of a new medical subspeciality.

When the 2nd edition of Beard's Fetal Medicine textbook appeared it had expanded by over 50\%: from 542 pages in 1976 to 823 pages in 1984 . With regard to 'spontaneous abortion', the 1976 1st edition referred only to the possible causative role of immunological factors; in 1984, the 2 nd edition text referred in seven separate entries to the potential significance of a variety of hormones, immunological and infective agents. The growing knowledge base of perinatology was addressing the problems of early pregnancy.

As Professor and Head of the Department of Obstetrics and Gynaecology in St Mary's Hospital, London, between 1972 and 1996, Richard William Beard was a forerunner in the process of perinatal medicine's subspecialisation. As well as his textbook on the subject, he published dozens of papers relaying the findings of his research in fetal physiology and monitoring. Beard was also a frequent letter-writer: the correspondence columns of the Lancet carry one or more of his contributions almost every year from the mid-1970s to mid-1980s. His letters evidence a concern for the improvement of women's experiences of health and healthcare ${ }^{37}$ as well as efforts to defend his professional interests. ${ }^{38}$ In the 'Miscarriage or abortion?' Lancet letter published in 1985, Beard was defining appropriate medical terminology for pregnancy loss and defining the subject's position within his subspeciality, and defining his own authority in that field.

\section{A WOMAN-CENTRED APPROACH}

Richard Beard's acknowledgement of women's emotional reactions to miscarriage and of the distress caused by the medical terminology of 'spontaneous abortion' suggests the influence of contemporaneous non-medical developments. Although miscarriage and the upset that it could cause women might have posed difficulties to feminists on account of its resonance with antiabortionist argument, some notable advocates sought to encourage a more woman-centred approach among health professionals.

The Miscarriage Association had been established in 1982 to offer information and support to women affected by pregnancy loss. Richard Beard acknowledged in his Lancet letter that 'the Miscarriage Association found that $85 \%$ of women who have had a miscarriage felt strongly that the word abortion should be changed'.

In 1984, sociologists Ann Oakley and Helen Roberts along with general practitioner Ann McPherson had published Miscarriage: the 'first British book of its kind on the subject'. Writing for 'women having miscarriages and those providing care for them', they sought to address 'the surprising lack of information that there is, especially in the areas of women's emotional reactions to miscarriage, and with respect to what is considered appropriate treatment by the professionals'. Early in the book the point about terminology ('miscarriage' preferred to 'abortion') was made emphatically and emotively. Richard Beard in his Lancet letter makes no reference to Oakley, McPherson and Roberts, but their analysis of the issue is echoed distinctly in his.

The early 1980s were a dynamic period for feminist politics. The high-profile and widely-reported case of Wendy Savage in 1985 prompted consideration within the medical profession of the role of women as doctors and as pregnant patients. ${ }^{i} \mathrm{~A}$ comprehensive BMJ write-up of the Savage case in June 1985 described 'a battle between the high tech, interventionist, hospital based school of obstetric practice and the community based, woman centred approach' of Savage. ${ }^{39}$ It was a battle undoubtedly won by the woman-centred approach. Richard Beard would align with that approach a few months later when he acknowledged that 'our patients always speak of 'miscarriages' and called for 'all health professionals, to start using the word miscarriage rather than abortion.'

\section{FUTURE MEANINGS}

The conscious distinction by doctors of 'miscarriage' from 'abortion' ('induced' and 'spontaneous') may be seen to have reflected certain legal, technical, professional and societal developments. The distinction in language may also be read as part of the process of assigning meaning to those women to whom the language was applied, a process by which women who experience miscarriage could be defined as distinct from women who experience an induced abortion. Future work should elaborate these meanings, but some initial impressions are offered below.

Political implications of Beard's 'Miscarriage or abortion?' letter became apparent only a fortnight after its publication when the Lancet printed a response from Caroline Woodroffe, then General Secretary of the Brook Advisory Centres. Woodroffe highlighted a further benefit of Beard's suggested change in terminology: that 'confusion in Parliament and public debate would also be reduced. ${ }^{40}$ Considerable public and

${ }^{i}$ Wendy Savage was suspended on full pay from her obstetric consultancy pending the outcome of an inquiry into allegations of malpractice. She was reinstated after a much-publicised campaign from local MPs, GPs and hundreds of protesters, and after it had become clear that she had been the victim of vested male professional interests. 
parliamentary debate followed shortly when David Alton introduced the Abortion (Amendment) Bill to parliament in autumn 1987. ${ }^{\text {ii }}$

Correspondence in the medical press around this time testifies to the strength of feeling among practitioners and the moral judgements of some doctors relating to abortion, both as an act ('killing foetuses') and as an implication about sexual behaviour. ${ }^{41}$ Beard refers tangentially to the moral stigma of abortion in his Lancet letter suggesting that: 'Most women associate the word with what in the past was an illegal act and therefore socially unacceptable...' For doctors (like Beard) dealing with women who had miscarried the distinction of 'miscarriage' from 'abortion' permitted the distinguishing of their patients (and themselves) from a subject that was heavily stigmatised and 'socially unacceptable'.

In his letter to the Lancet, Beard portrays women who miscarry using the following words and phrases: 'unmitigated misery', 'fortitude', 'deep disappointment', 'uncomplaining' and 'at their lowest ebb', an image of suffering consolidated by his final appeal for change 'on humanitarian grounds'. Meanwhile, he uses no adjectives or emotional descriptors in referring to women who experience abortion (potentially a very difficult life-event). Nor does Beard consider what significance the 'socially unacceptable' term 'abortion' might carry for women who seek a termination of pregnancy (a decision that might be made for a great variety of reasons by women in many different circumstances). Beard's letter demonstrates a selective empathy and represents a construction of the sensitivities of women who experience miscarriage as much as a response to those sensitivities. The distinction in language of 'miscarriage' from 'abortion' at this moment in history facilitated the splitting of two groups of women who could potentially be very differently constructed.

After Beard in 1985 asked 'doctors, indeed all health professionals, to start using the word miscarriage rather than abortion for a spontaneous pregnancy loss', other medical authors subsequently wrote articles whose titles addressed 'Terminology used in early pregnancy loss' 2 and advocated that 'Terminology for early pregnancy loss must be changed'. ${ }^{42}$ In each of these instances use of the term 'miscarriage' rather than 'abortion' was advised. Whether or not we perceive that the term 'miscarriage' (as might be suggested) implies an inherent accusation in its literal allusion to a pregnancy miscarried by the mother's womb or that (as might be speculated) the phrase 'spontaneous abortion' ciphers ideas of hysteria and a typically irrational womb impulsively ejecting its content, it is quite apparent that neither of these two terms overtly acknowledges a pregnancy, or

\footnotetext{
iiThe Bill proposed reducing the upper limit for abortion from 28 to 18 weeks. Although the David Alton's 1988 Abortion (Amendment) Bill ultimately failed, it shifted the focus in abortion debates toward the issue of the lower limit of fetal viability. At the time this was acknowledged by members of the medical profession to be 24 weeks. Consequently, when an amendment to the Abortion Act was included in the 1990 Human Fertilisation and Embryology Act, it redefined the upper limit for abortion: reducing it from 28 to 24 weeks. This legal defining of potential fetal viability in the context of abortion determined the terms of the 1992 Still-Birth (Definition) Act. That 1992 Act stipulated that, for the purposes of registration of births and deaths, the diagnostic cut-point between still-birth (the registered intrauterine death of a potentially-viable fetus) and miscarriage (the non-registered demise of a non-viable fetus) would also be reduced from 28 to 24 weeks. Despite efforts to distinguish them, in 1992, as in 1967, miscarriage, its margins and its meanings were once more being defined by the law relating to abortion.
}

a loss. The fact that the phrase 'pregnancy loss' was repeatedly employed by medical authors writing on the subject for other doctors, but was apparently not considered suitable for use in front of, or by, women themselves, is notable. The reluctance of doctors to offer 'pregnancy loss' to women as a possible descriptor might suggest a professional denial of the experience or persisting professional efforts to maintain some sort of control.

Following Beard's appeal to doctors and the shift in medical language, there appears to have been less of a shift in the depth of actual woman-centredness likely to be found within the medical profession or in the degree of real empathy likely to be extended toward women who miscarried. Two clinical review papers on the subject of miscarriage published in the $B M J$ since the turn of the century contained no allusion to potential distress and emotional upset. ${ }^{43}{ }^{44}$ Conversely, during the 1990 s and 2000s, medical researchers advocating for improved care after miscarriage tended to emphasise the 'psychiatric morbidity, including anxiety and depression' among women and highlight 'psychiatric cases': ${ }^{45} 46$ arguably, by these and other means, miscarriage has tended to be pathologised, perhaps perceived as a potential precursor of psychiatric illness, rather than being acknowledged as a troubling event in its own right, one that lies within the breadth of human experience and that warrants greater physician empathy.

\section{DISCUSSION}

The clinical terminology applied to women's health experiences in Britain changed after the mid-1980s when doctors consciously began using the term 'miscarriage' instead of 'abortion' to refer to early pregnancy loss. In this essay I have sought to convey the meaning of this change in language: the factors behind it and its subsequent significance. Until now, Richard Beard's 1985 letter to the Lancet has tended to be perceived as an isolated stimulus to the shift in medical language and as a spontaneous response to women's feelings. However, evidence from medical journals and textbooks of the time reveals how Beard's letter and the change in medical language can be better understood in the context of certain historical developments that enabled and encouraged both the letter-writing and language shift.

From the late 1960s onwards, the changes in Britain's legislation allowing women greater access to abortion services also enabled them to discuss these issues with doctors without fear of being criminalised. In turn, doctors could engage in conversations with women without concern that they were being deceived: specifically, they could be confident that women describing symptoms of spontaneous pregnancy loss were not concealing a deliberate (and previously illegal) termination. Doctors' terminology for early pregnancy loss could now refer to something actually knowable. By the 1980s, developments in ultrasound technology enabled the content of a woman's uterus and any early pregnancy pathologies to be visualised in real time. Doctors were now able to apply their terminology diagnostically in the clinic.

For the first time in the medical history of early pregnancy loss, following the legal and technological developments described above, diagnostic language could be immediately coupled to a clinically knowable reality. For clinicians, this would have conferred greater significance upon the medical terminology and may have heightened consciousness of language in this context. Meanwhile, the need to define accurate and unambiguous terminology for describing diagnoses of fetal loss would have been given impetus by rapidly expanding medical knowledge of the fetus and the establishment of a new fetal- 
focused medical speciality. Consistent with this, the communication that sought to define the terminology came from a senior figure at the forefront of this burgeoning speciality.

The emotional experiences of women who miscarry were the most proximal stimulus to Richard Beard's writing and the justification that he refers to in his letter. Most probably, given the temporality of other writing on this issue, these experiences were acknowledged after being channelled by women's associations and feminist commentators. The fact that the emotional experiences of women formed the basis for Beard's appeal to doctors suggests that these experiences, in theory at least, had some importance for clinicians, reflecting a growing value placed upon empathy and the patient's experience.

Despite the prominence of empathy implied in the call for doctors to use the term 'miscarriage' instead of 'abortion' when referring to early pregnancy loss, it is doubtful whether the subsequent shift in language among clinicians was accompanied by any similar shift toward more genuinely empathic medical care for women who experienced miscarriage. Conceivably, the emphasis upon 'empathic' terminology made the real challenge (an empathetic response to the loss not only of a pregnancy, but of an expected child, motherhood and apparent certainties) appear amenable to a simple technical solution (the substituting of one word for another). This may have aided the language shift among doctors, and brought some small improvement to the experiences of women who miscarried, but it did not necessarily betoken a more empathic or women-centred approach.

In 1998, a BMJ editorial wondered whether using the term 'miscarriage' rather than 'abortion' was really the medical profession's most effective intervention in the context of pregnancy loss. It warned that changing medical language 'while laudable in its intentions, may not be enough to alleviate mothers' dissatisfaction with the care that they receive. The risk is that mere use of 'correct' terminology... could lead to professional complacency. 47

The importance of ensuring appropriate standards of care is underscored by the estimation that one in five pregnancies will miscarry, and most of these women will seek medical attention. Research findings have demonstrated repeatedly that mothers' dissatisfaction with medical care in the context of early pregnancy loss has not yet been alleviated in Britain. ${ }^{48} 49$ In October 2011, the internet based charity 'Mumsnet' felt compelled to launch a campaign for 'Better Miscarriage Care'. ${ }^{50}$ The first ever NHS guideline dealing specifically with the issue of miscarriage was published in December 2012; it placed considerable emphasis upon the need for support, information-giving and the offer of follow-up for women. ${ }^{51}$ This may represent a significant development, but the shift of medical language from 'abortion' to 'miscarriage' reminds us that it will take more than words to truly improve patients' experiences.

Acknowledgements The author profusely thanks Eike Adams.

Competing interests None.

Provenance and peer review Not commissioned; externally peer reviewed.

Open Access This is an Open Access article distributed in accordance with the Creative Commons Attribution Non Commercial (CC BY-NC 3.0) license, which permits others to distribute, remix, adapt, build upon this work non-commercially, and license their derivative works on different terms, provided the original work is properly cited and the use is non-commercial. See: http://creativecommons.org/ licenses/by-nc/3.0/

\section{REFERENCES}

1 Beard RW, Mowbray JF, Pinker GD. Miscarriage or abortion? Lancet 1985:2:1122-23
2 Chalmers B. Terminology used in early pregnancy loss. Br J Obstet Gynaecol 1992;99:357-8

3 Chamberlain G. Nomenclature: what is your name? BMJ 1997:314:1684.

4 Lee E. Abortion law and politics today. London: Macmillan, 1998:5-94.

5 Franklin S, Lury C, Stacey J. Off Centre: feminism and cultural studies. London: Harper Collins Academic, 1991:129-218.

6 Oakley A. A history lesson: ultrasound in obstetrics. In: Oakley A, ed. Essays on women, medicine and health. Edinburgh: Edinburgh University Press, 1993:189-97.

7 Oakley A. The captured womb: history of the medical care of pregnant women. Oxford: Blackwell, 1984

8 Lee E. Abortion, motherhood, and mental health: medicalizing reproduction in the United States and Great Britain. New York: Aldine de Gruyter, 2003.

9 Layne L. Motherhood lost: a feminist account of pregnancy loss in America. New York: Routledge, 2003: 9-40.

10 Layne L. A women's health model for pregnancy loss: a call for a new standard of care. Feminist Studies 2006;32:573-600.

11 Everett C, Ashurst H, Chalmers I. Reported management of threatened miscarriage by general practitioners in Wessex. BMJ 1987;295:583-6.

12 Stoddart PGP, Houlton M. Reported management of threatened miscarriage by general practitioners in Wessex. BMJ 1987;295:998.

13 Entwistle CC, Bowell PJ, Tovey LAD. Reported management of threatened miscarriage by general practitioners in Wessex. BMJ 1987;295:998.

14 Regan L. Recurrent miscarriage. BMJ 1991;302:543-4

15 Lewis PJ. Recurrent miscarriage. BMJ 1991;302:1078.

16 MacLean MA, Wilson R, Walker JJ. Recurrent abortion. BMJ 1991;302:909.

17 Lawrence RA. Use of the word "abortion". BMJ 1988;296:792.

18 Perera WSE. Management of cases of abortion. BMJ 1961;1:705.

19 Bender S. Bleeding in early pregnancy. BMJ 1964;1:1093-6.

20 Robinson HP. The diagnosis of early pregnancy failure by sonar. $\mathrm{Br} J$ Obstet Gynaecol 1975;82:849-57.

21 Duff GB. Prognosis in threatened abortion: a comparison: between predictions made by sonar, urinary hormone assays and clinical judgement. $\mathrm{Br} J$ Obstet Gynaecol 1975;82:858-62.

22 Duff $G B$, Evans JJ, Legge M. A study of investigations used to predict outcome of pregnancy after threatened abortion. Br J Obstet Gynaecol 1980;87: 194-8.

23 Mantoni M, Pederson JF. Intrauterine haematoma an ultrasonic study of threatened abortion. Br J Obstet Gynaecol 1981;88:47-51.

24 Anderson RS, Phillips PJ. Routine real-time scanning at the first hospital visit. $\mathrm{Br}$ J Obstet Gynaecol 1982;89:16-19.

25 Wilson RD, Kendrick V, Wittmann BK, et al. Risk of spontaneous abortion in ultrasonically normal pregnancies. Lancet 1984;2:920-1.

26 Christiaens GCM, Stoutenbeek Ph. Spontaneous abortion in proven intact pregnancies. Lancet 1984;2:571-2.

27 Everett $\mathrm{C}$, Ashurst $\mathrm{H}$, Chalmers I. Reported management of threatened miscarriage by general practitioners in Wessex. BMJ 1987;295:583-6.

28 Haxton MJ, Bell J. Fetal anatomical abnormalities and other associated factors in middle-trimester abortion and their relevance to patient counselling. $\mathrm{Br} J$ Obstet Gynaecol 1983;90:501-6.

29 Mills AM. An assessment of pre-operative microbial screening on the prevention of post-abortion pelvic inflammatory disease. Br J Obstet Gynaecol 1984;91: 182-6.

30 Pickering RM, Forbes JF. Risks of preterm delivery and small-for-gestational age infants following abortion: a population study. Br J Obstet Gynaecol 1985;92:1106-12.

31 Evans DR. Neural-tube defects: importance of a history of abortion in aetiology. BMJ 1979;1:975-6.

32 MacHenry JCRM, Nevin NC, Merret JD. Comparison of central nervous system malformations in spontaneous abortions in Northern Ireland and south-east England. BMJ 1979;1:1395-7.

33 Kline J, Shrout $P$, Stein $Z$, et al. Drinking during pregnancy and spontaneous abortion. Lancet 1980;2:176-80.

34 Harlap S, Shiono PH. Alcohol, smoking, and incidence of spontaneous abortions in the first and second trimester. Lancet 1980;2:173-6.

35 Firkin BG, Howard MA, Radford N. Possible relationship between lupus inhibitor and recurrent abortion in young women. Lancet 1980;2:366.

36 Lubbe WF, Butler WS, Palmer SJ, et al. Fetal survival after prednisolone suppression of maternal lupus-anticoagulant. Lancet 1983;1:1361-63.

37 Beard RW, Capel K. A better environment for women in labour. Lancet 1985;2:1059.

38 Beard RW, Braude P, Mowbray JF, et al. Protective antibodies and spontaneous abortion. Lancet 1983:2:1090.

39 Dyer C. The Savage case: disciplining consultants. BMJ 1985;290:1894-95.

40 Woodroffe C. Miscarriage or abortion. Lancet 1985;2:1245.

41 White M. Late abortions and the law. BMJ 1988;296:715-16.

42 Hutchon DJR, Cooper S. Terminologyfor early pregnancy loss must be changed. BMJ 1998;317:1081. 
43 Ankum WM, Wieringa-de Waard M, Bindels PJ. Management of spontaneous miscarriage in the first trimester: an example of putting informed shared decision making into practice. BMJ 2001;322:1343.

44 Sotiriadis A, Papatheodorou S, Makrydimas G. Threatened miscarriage: evaluation and management. BMJ 2004:329:152.

45 Thapar AK, Thapar A. Psychological sequelae of miscarriage: a controlled study using the general health questionnaire and the hospital anxiety and depression scale. Br J Gen Pract 1992;42:94-6.

46 Wong MK, Crawford TJ, Gask L, et al. A qualitative investigation into women's experiences after a miscarriage: implications for the primary healthcare team. $\mathrm{Br}$ Gen Pract 2003;53:697-702.
47 Freeling P, Gask L. Sticks and stones: changing terminology is no substitute for good consultation skills. BMJ 1998;317:1028

48 Simmons RK, Singh G, Maconochie N, et al. Experience of miscarriage in the UK: qualitative findings from the National Women's Health Study. Soc Sci Med 2006:63:1934-46.

49 Geller PA, Psaros C, Kornfield SL. Satisfaction with pregnancy loss aftercare: are women getting what they want? Arch Womens Ment Health 2010;13:111-24.

50 Moscrop A. Scans, misogyny, and miscarriage. BMJ 2011;343:d7960.

51 National Institute for Health and Clinical Excellence. Ectopic pregnancy and miscarriage: diagnosis and initial management in early pregnancy of ectopic pregnancy and miscarriage. (Clinical guideline 154.) 2012. http://www.nice.org.uk/CG154 